\title{
Impact of IGF(CA)19 gene polymorphism on the metabolic response to GH therapy in adult GH-deficient patients
}

\author{
C Giavoli ${ }^{1,2}$, E Profka ${ }^{1,2}$, E Sala ${ }^{1,2}$, M Filopanti, ${ }^{1,2}$ A M Barbieri ${ }^{1,2}$, S Bergamaschi ${ }^{1,2}$, \\ E Ferrante $^{1,2}$, M Arosio ${ }^{1,3}$, B Ambrosi ${ }^{4}$, A G Lania ${ }^{5,6}$, A Spada ${ }^{1,2}$ and P Beck-Peccoz ${ }^{1,2}$ \\ ${ }^{1}$ Department of Clinical Sciences and Community Health, University of Milan, Milan, Italy, ${ }^{2}$ Endocrinology and \\ Diabetology Unit, Fondazione IRCCS Ca' Granda, Ospedale Maggiore Policlinico, Via Francesco Sforza, 35, \\ 20122 Milan, Italy, ${ }^{3}$ Unit of Endocrine Diseases and Diabetology, Ospedale San Giuseppe, Multimedica, Milan, Italy, \\ ${ }^{4}$ Endocrinology and Diabetology Unit, Department of Medical and Surgical Sciences, University of Milan, IRCCS \\ Policlinico San Donato, San Donato Milanese, Milan, Italy ${ }^{5}$ Biometra Department, University of Milan, and \\ ${ }^{6}$ Endocrine Unit, Humanitas Cinical and Research Center, Rozzano, 20089 Milan, Italy
}

\author{
Correspondence \\ should be addressed \\ to C Giavoli \\ Email \\ claudiagiavoli@yahoo.it
}

\section{Abstract}

Objective: A polymorphism in the promoter region of the IGF1 gene has been linked to serum IGF1 levels, risk of diabetes, and cardiovascular diseases with conflicting results. The aim of this study was to investigate the impact of this polymorphism on the short-term ( 1 year, $n=98$ ) and long-term (5 years, $n=50$ ) metabolic response to recombinant human $\mathrm{GH}(\mathrm{rhGH})$ in GH-deficient (GHD) adults.

Design and methods: Prospective study on GHD adults. Different genotypes were studied by microsatellite method. According to the most frequent 192 bp allele (19 cytosine-adenosine-repeats), subjects were divided into homozygous (19/19), heterozygous (19/X), and noncarriers (X/X).

Results: Basal characteristics of patients as well as their response to rhGH in terms of decrease in body fat percentage and increase in IGF1 levels were not different in the three genotype-groups. Conversely, after 1-year rhGH, a significant worsening of insulin sensitivity (i.e. increase in fasting glucose levels and homeostasis model assessment of insulin resistance) and a significant improvement in lipid profile (i.e. reduction in total cholesterol and LDL-cholesterol) were recorded only in homozygous subjects. In the long-term, insulin sensitivity was restored in all the patients, while a significant improvement in lipid profile was observed in homozygous and heterozygous subjects, but not in noncarrier subjects. No difference in rhGH dose among groups was recorded throughout the study.

Conclusions: In GHD adults, the presence of the WT allele in the IGF1 gene promoter may enhance sensitivity to either negative or positive metabolic changes induced by rhGH.

\section{Introduction}

Growth hormone deficiency (GHD) in adults is a clinical syndrome characterized by several metabolic alterations such as increased body fat percentage (BF\%), impaired physical performance, altered lipid profile, and insulin resistance. Many reports support efficacy of recombinant human $\mathrm{GH}$ (rhGH) replacement therapy in reversing most of the above-mentioned alterations $(1,2,3)$. As suggested by recent guidelines (4), GH replacement in adults should be started with low doses, thereafter titrated and individualized according to insulin-like growth factor 1 (IGF1) levels and clinical conditions of the patients $(4,5)$, in order to obtain the best efficacy, minimizing sideeffects. Nowadays, it is well established that the individual response to rhGH is highly variable and, in the last years,
(C) 2014 European Society of Endocrinology Printed in Great Britain
Published by Bioscientifica Ltd. 
some pharmacogenetics studies have tried to find a possible explanation for this inter-individual variability, as genetic factors could play a role in the response to $\mathrm{rhGH}$ in GHD adults.

Namely, a common polymorphism of the GH receptor (GHR d3/fl) has been extensively studied. As the d3-GHR isoform has been shown to have an increased receptor activity due to an enhanced signal transduction $(6,7)$, various authors have studied the relationship between the efficacy of rhGH therapy and this polymorphism, especially in children, as summarized in a quite recent systematic review by Wassenaar et al. (8). Regarding adults, our group has recently reported that the functional difference of d3-GHR may confer major sensitivity to metabolic effects of rhGH in GHD adults (9).

As IGF1 is the main GH effector, a number of studies have also examined polymorphisms of the IGF1 gene. In particular, a highly polymorphic microsatellite comprising a variable length of a cytosine-adenosine (CA) repeat sequence $(n=10-24)$ has been identified in the promoter region of $I G F 1$ gene, $1 \mathrm{~kb}$ upstream from the transcription site. The number of CA repeats ranges between 10 and 24 and the most common allele in the Caucasian population contains 19(CA) (192 bp) repeats (10). This microsatellite has been linked to IGF1 levels, risk of diabetes, and cardiovascular diseases in different populations, with conflicting results $(10,11,12,13,14,15,16)$.

Regarding pathological conditions of $\mathrm{GH}$ secretion, various studies have been performed in short children while in adults, there are up to now two reports in the literature about this topic. In particular, Akin et al. (17) evaluated a cohort of acromegalic subjects and found that patients having $>194$ bp genotype (more than $20 \mathrm{CA}$ repeats) have higher IGF1 levels and require higher dose medication than patients with $<192$ or $192-194 \mathrm{bp}$ genotype. In turn, Meyer et al. (18) investigated a possible association between the 19(CA) polymorphism and $\mathrm{GH}$ dose in GHD adults and did not find any correlation between the number of CA repeats and the responsiveness to rhGH, at least in terms of IGF1 levels. No data are so far available about an eventual relationship between this polymorphism and the metabolic changes induced by rhGH in GHD adults, changes known to differ from patient-to-patient. Thus, the aim of this study was to investigate the impact of the IGF(CA)19 gene polymorphism on basal phenotype and on shortand long-term response to rhGH in GHD adults, especially in terms of body composition, glucose, and lipid metabolism.

\section{Subjects and methods}

\section{Patients and study design}

This was a prospective study on 98 GHD adults $(M=60$, $\mathrm{F}=38$, mean age $46 \pm 13$ years). Ninety-nine healthy age and sex-matched subjects were recruited as controls for genetic analysis. Diagnosis of severe GHD was defined by a $\mathrm{GH}$ peak $<3 \mu \mathrm{g} / 1$ to insulin tolerance test (19) or $<11.5 \mu \mathrm{g} / \mathrm{l}$ if BMI was below $25 \mathrm{~kg} / \mathrm{m}^{2},<8.0 \mu \mathrm{g} / \mathrm{l}$ if BMI was between 25 and $30 \mathrm{~kg} / \mathrm{m}^{2}$, and $<4.2 \mu \mathrm{g} / \mathrm{l}$ if BMI was over $30 \mathrm{~kg} / \mathrm{m}^{2}$ to arginine $+\mathrm{GHRH}$ test (20). The causes of GHD were nonfunctioning pituitary adenoma $(n=33)$, prolactinoma $(n=20)$, craniopharyngioma $(n=16), \mathrm{GH}-$ secreting adenoma $(n=8)$, Cushing's disease $(n=4)$, idiopathic $(n=7)$, primary empty-sella $(n=4)$, traumatic brain injury $(n=2)$, Rathke cleft cysts $(n=2)$, and other hypothalamic-pituitary diseases $(n=2$, one meningioma and one histiocytosis). All patients with childhood-onset GHD $(n=10)$ were appropriately retested before the beginning of rhGH replacement in adult life. Seven patients had isolated GHD and 91 had multiple pituitary hormone deficiencies variously associated. Diabetes insipidus was present in $22 \%$ of subjects. Pituitary function was determined with basal or dynamic evaluation, as appropriate. In particular, central hypothyroidism was defined as low free thyroxine $\left(\mathrm{FT}_{4}\right)$ levels in the presence of inappropriate thyroid-stimulating hormone levels. Central hypoadrenalism was defined as a lack of response to stimulation tests (peak cortisol levels lower than $500 \mathrm{nmol} / \mathrm{l}$ during standard-dose $(250 \mu \mathrm{g})$ corticotropin stimulation test or insulin tolerance test). Central hypogonadism was diagnosed in case of low testosterone or estradiol levels and inappropriately normal or low gonadotropin levels. When necessary, conventional hormone replacement therapy for other pituitary hormone deficiencies was given at stable doses for at least 3 months before beginning rhGH therapy. In particular, all patients with central hypoadrenalism received a dose of $25 \mathrm{mg} /$ day cortisone acetate, while other replacement therapies were adjusted according to hormonal results. Moreover, as it is known that rhGH therapy may unmask or worsen a central hypothyroid or hypoadrenal state $(21,22)$, both hypothalamus-pituitary-thyroid and -adrenal axis were re-evaluated not later than 6 months after the beginning of rhGH and replacement therapy was started or adjusted, when necessary. One-year effects were evaluated in all 98 patients, whereas in 50 of them a 5-year follow-up was available due to an earlier starting date of rhGH. Initial mean rhGH dose was 0.2 and $0.3 \mathrm{mg} /$ day in men and in 
women, respectively, then individually titrated against IGF1 levels between 0 s.D. and below the upper limit of the age- and sex-related reference range, as evaluated after 3 months of therapy. Mean rhGH dose was $0.31 \pm 0.17$ and $0.36 \pm 0.17 \mathrm{mg} /$ day after 1 and 5 years respectively. There was no difference in rhGH dose among the three genotype-groups at any time of the study. Informed consent was obtained from all participants and the study was approved by the Local Ethics Committee.

\section{Study parameters and assays}

In all the patients, several metabolic parameters such as serum fasting glucose (FG) and fasting insulin (FI), HbA1c, and lipid profile (total cholesterol and HDL-cholesterol, triglycerides (TG)) were evaluated. Insulin resistance degree was determined using the homeostasis model assessment of insulin resistance (HOMA-IR $=\mathrm{FI}$ $(\mathrm{mU} / \mathrm{l}) \times \mathrm{FG}(\mathrm{mmol} / \mathrm{l}) / 22.5)(23)$. Serum IGF1 levels were measured by a chemiluminescent immunometric assay (Immulite 2000 IGF1; Siemens Medical Solutions Diagnostics, Los Angeles, CA, USA), with an intra- and interassay coefficient of variation of 2.9 and $7.4 \%$ respectively. IGF1 SDS was calculated from age- and sex-dependent reference ranges. All the other biochemical parameters were measured by standard procedures. LDL-cholesterol levels were evaluated by the formula: $\mathrm{LDLc}=$ total cholesterol $-\mathrm{HDLc}-\mathrm{TG} / 5$ (24).

\section{Anthropometric measurements}

Body composition was evaluated by whole-body bioelectrical impedance analysis, using a portable impedance analyzer (RJL Systems, Detroit, MI, USA), following the instruction given by the manufacturer. BF\% was calculated using Segal's regression equation (25) and the results were compared with those reported by Pichard et al. (26) in normal subjects matched for age and sex. BMI was calculated as weight in kilograms divided by the square of height in meters.

\section{DNA extraction and genetic analysis}

In all 98 GHD patients and in 99 control subjects, leukocyte DNA was extracted from blood samples using Nucleon BACC2 genomic DNA purification kit (GE Healthcare, Piscataway, NJ, USA) in compliance with the manufacturer's instructions. A multiplex PCR was carried out to determine the IGF(CA)19 gene polymorphism using a specific primer for the IGF1(CA) 19 area (forward primer, $5^{\prime}$-FAM-GCT AGC

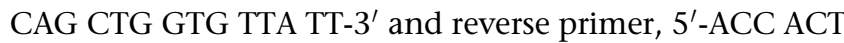
CTG GGA GAA GGG TA-3'). PCR was carried out in a $25 \mu \mathrm{l}$ reaction mix with Platinum Taq (Invitrogen) and subjected to denaturation at $96^{\circ} \mathrm{C}$ for $5 \mathrm{~min}$, followed by 35 cycles at $95^{\circ} \mathrm{C}$ for $30 \mathrm{~s}, 59^{\circ} \mathrm{C}$ for $30 \mathrm{~s}, 72^{\circ} \mathrm{C}$ for $30 \mathrm{~s}$, and a final extension at $72{ }^{\circ} \mathrm{C}$ for $5 \mathrm{~min}$. Amplification products were subsequently run on $1 \%$ agarose gel electrophoresis. One microliter of PCR product was then loaded into a 96 wellplate with the specific markers of known molecular weights to then proceed to the analysis of the size/height/area of the peaks generated by the electrophoretic run. In each well of the plate were added $1 \mu \mathrm{l}$ PCR product, $0.2 \mu \mathrm{l}$ Gene ScanLiz 500-SIZE STANDARD (Applied Biosystems), and $10 \mu \mathrm{l}$ formamide. The well-plate was then analyzed by capillary electrophoresis using a 3100 Genetic Analyzer (Perkin-Elmer Corp., Waltham, MA, USA). All raw data were analyzed with the bioinformatic software Peak Scanner, version 1.0 (Applied Biosystems).

\section{Statistical analysis}

Calculations were performed by SPSS for Windows, version 17.0 (SPSS). The data are expressed as mean \pm s.D., whereas proportion and frequencies were used for categorical variables. Normal distributed variables were compared using Student's $t$-test among the groups of patients and within each group at 0-1-5 years. Levene's test was performed first to check the equality of variances. Categorical variables were compared by Fisher or $\chi^{2}$-test, where appropriate.

In order to assess the role of confounders, i.e. sex, age at diagnosis, and metabolic syndrome (MS), linear multiple regression analyses were carried out on metabolic parameters measured during follow-up. A twotail $P<0.05$ was considered statistically significant. In multiple comparisons tests, Bonferroni's correction of $\alpha$ value was used.

\section{Results}

\section{Baseline: GHD genotype and phenotype}

According to the most frequent 19(CA) repeat allele (192 bp), patients were divided into homozygous (19/19, $n=38,38.7 \%)$, heterozygous (19/X, $n=44,44.8 \%)$, and noncarriers (X/X, $n=16,16.3 \%)$. Allele frequency was not different in GHD patients compared with controls and conformed with the Hardy-Weinberg equilibrium.

At baseline, most of the patients had IGF1 levels below the normal range for age and sex (61\%), in particular IGF1 
levels were low in 30 out of 38 (78\%), 30 out of $44(68 \%)$, and nine out of 16 (56\%) patients of 19/19, 19/X, and X/X groups respectively. Though these proportions seemed to follow a decreasing trend from patients homozygous to patients noncarrying the WT allele, no significant difference was observed at $\chi^{2}$-test $(P=0.54)$. BF\% was significantly higher in noncarriers than in heterozygous and homozygous ( $37 \pm 8$ vs $30 \pm 9$ and $31 \pm 9$ respectively, $P<0.02)$ subjects.

No differences were found in FG, HbA1c, insulin, total cholesterol, HDL-cholesterol, and (TG) levels among the three genotype-groups. Demographic and clinical data, as well as comparison of basal parameters among the three different genotypes, are presented in Table 1.

According to previously established criteria (27), diagnosis of MS was made in nine patients (one in $19 / 19$, three in $19 / X$, and five in $X / X)$. Prevalence of MS was significantly higher in the $\mathrm{X} / \mathrm{X}$ group $(P<0.001$ at $\chi^{2}$-test). Basal prevalence of MS as well as of its individual components is presented in Table 1. At the beginning of the study, 12 subjects (three in 19/19, five in 19/X, and four in $\mathrm{X} / \mathrm{X}$ group) were taking lipid-lowering agents and 12 (six in 19/19, three in $19 / \mathrm{X}$, and three in $\mathrm{X} / \mathrm{X}$ group) were taking antihypertensive drugs. These therapies remained unchanged throughout the study.

\section{One-year period: effects of rhGH and pharmacogenetics}

After 1 year of rhGH replacement, in the whole cohort of patients, mean IGF1 levels significantly increased (IGF1 SDS from $-2.0 \pm 0.9$ to $-0.4 \pm 1.2, P<0.01$ ) and $\mathrm{BF} \%$ significantly decreased (from $32 \pm 8$ to $30 \pm 8 \%, P<0.01$ ). Regarding metabolic parameters, FG and FI significantly increased (from $81 \pm 9$ to $85 \pm 9 \mathrm{mg} / \mathrm{dl}$ and from $9.3 \pm 7$ to $11.2 \pm 9.3 \mu \mathrm{IU} / \mathrm{ml}$ respectively, $P<0.01$ ), thus reflecting an initial worsening of insulin sensitivity, as mirrored by a significant increase in HOMA-IR (from $1.9 \pm 1.5$ to $2.4 \pm 1.9, P<0.01)$. Total cholesterol and LDL-cholesterol significantly decreased (from $215 \pm 44$ to $201 \pm 42$ and from $136 \pm 43$ to $121 \pm 40 \mathrm{mg} / \mathrm{dl}$ respectively, $P<0.01$ ), while HDL-cholesterol did not change. Interestingly, when analyzing rhGH effects according to the three IGF1 genotypes, while the magnitude and significance of increase in IGF1 levels were not different, the worsening of insulin sensitivity and the improvement in lipid profile were significantly different only in homozygous patients. Statistical analysis among the three genotype-groups did not reveal any significant differences in 1 year rhGH effects on the evaluated parameters. As observed at baseline in noncarriers, a higher $\mathrm{BF} \%(28 \pm 8,27 \pm 9$, and $35 \pm 8 \%$ in $19 / 19,19 / \mathrm{X}$, and $\mathrm{X} / \mathrm{X}$ respectively, $P<0.01)$ and a higher

Table 1 Clinical characteristics of the 98 GHD patients and basal prevalence of MS and of its individual components: comparison between the three genotype-groups.

\begin{tabular}{|c|c|c|c|}
\hline & $19 / 19(n=38)$ & $19 / X(n=44)$ & $\mathbf{X} / \mathbf{X}(n=16)$ \\
\hline \multicolumn{4}{|c|}{ Clinical characteristics of the 98 GHD patients } \\
\hline Age (years) & $47 \pm 15$ & $45 \pm 15$ & $44 \pm 13$ \\
\hline $\operatorname{Sex}(M / F)$ & $27 / 11$ & $28 / 16$ & $6 / \overline{10}$ \\
\hline BMI $\left(k g / m^{2}\right)$ & $27 \pm 4$ & $26 \pm 6$ & $27 \pm 5$ \\
\hline $\mathrm{BF} \%$ & $31 \pm 9$ & $30 \pm 9$ & $37 \pm 8 *$ \\
\hline IGF1 (SDS) & $-2.0 \pm 1.1$ & $-1.9 \pm 0.9$ & $-1.9 \pm 0.7$ \\
\hline $\mathrm{HbA1c}(\%)$ & $5.0 \pm 0.6$ & $4.9 \pm 1.1$ & $4.9 \pm 0.8$ \\
\hline FG (mg/dl) & $82 \pm 8$ & $78 \pm 17$ & $83 \pm 10$ \\
\hline $\mathrm{FI}(\mu \mathrm{IU} / \mathrm{ml})$ & $8 \pm 5$ & $9 \pm 5$ & $10 \pm 5$ \\
\hline HOMA & $1.7 \pm 1.0$ & $1.8 \pm 1.6$ & $2.1 \pm 1.1$ \\
\hline T-chol (mg/dl) & $215 \pm 43$ & $215 \pm 44$ & $216 \pm 53$ \\
\hline HDL-chol (mg/dl) & $53 \pm 17$ & $51 \pm 17$ & $51 \pm 14$ \\
\hline TG $(\mathrm{mg} / \mathrm{dl})$ & $131 \pm 53$ & $131 \pm 66$ & $147 \pm 60$ \\
\hline LDL-chol (mg/dl) & $138 \pm 38$ & $137 \pm 41$ & $136 \pm 52$ \\
\hline \multicolumn{4}{|c|}{ Basal prevalence of MS and of its individual components } \\
\hline $\begin{array}{l}\mathrm{HDL}<40(\mathrm{M}) \text { and } \\
<50(\mathrm{~F})(\mathrm{mg} / \mathrm{dl})\end{array}$ & 37 & 36 & 19 \\
\hline $\mathrm{TG}>150(\mathrm{mg} / \mathrm{dl})$ & 24 & 23 & 31 \\
\hline $\mathrm{FG}>110(\mathrm{mg} / \mathrm{dl})$ & 0 & 0 & 0 \\
\hline$W C>102(\mathrm{M})>88(\mathrm{~F})(\mathrm{cm})$ & 18 & 20 & 56 \\
\hline MS & 3 & 7 & $31 *$ \\
\hline
\end{tabular}

${ }^{*} P<0.01 \mathrm{X} / \mathrm{X}$ vs $19 / \mathrm{X}$ and 19/19. M, male; F, female; BF, body fat; FG, fasting glucose; FI, fasting insulin; T-chol, total cholesterol; TG, triglycerides; WC, waist circumference; BP, blood pressure; MS, metabolic syndrome. 
MS prevalence than in other genotype groups $(n=10$, two in 19/19, one in 19/X, and seven in $X / X, P<0.001$ at $\chi^{2}$-test) were observed. Distribution and prevalence of the individual components of the MS did not change after the 1-year rhGH treatment period (data not shown).

Regarding hypothalamic-pituitary-adrenal and -thyroid axis, central hypoadrenalism was newly diagnosed in six patients (two in 19/19, three in 19/X, and one in $\mathrm{X} / \mathrm{X}$ group), in whom hydrocortisone replacement was promptly started and central hypothyroidism, documented by low $\mathrm{FT}_{4}$ levels, was detected in ten patients (four in 19/19, four in 19/X, and two in $\mathrm{X} / \mathrm{X}$ ) and $\mathrm{L}-\mathrm{T}_{4}$ therapy was started $(n=7)$ or increased $(n=3)$ as needed.

The present results still hold significance after consideration of possible confounders such as sex, age at diagnosis, and presence of MS and BF\%. No difference in rhGH dose was observed among the three groups. $\mathrm{GH}$ effects in the three different genotypes are presented in Table 2.

\section{Five-year period: effects of rhGH and pharmacogenetics}

In the 50 patients evaluated after long-term treatment, IGF1 normalization was maintained and BF\% further decreased (from $32 \pm 8$ to $29 \pm 8$ and to $27 \pm 8 \%$, at baseline and after 1 and 5 years respectively, $P<0.01)$. Similarly, the reduction in total cholesterol and LDL-cholesterol observed at 1 year was confirmed after 5 years (from $208 \pm 50$ to $191 \pm 41 \mathrm{mg} / \mathrm{dl}$ and from $135 \pm 44$ to $111 \pm 6 \mathrm{mg} / \mathrm{dl}$ respectively, $P<0.01)$. Analyzing separately the three genotype-groups, improvement in lipid profile was significant only in $19 / 19$ and $19 / \mathrm{X}$ patients, i.e. in those bearing at least a WT allele. As far as rhGH effects on glucose metabolism on the whole cohort, both FG and FI levels after a short-term increase returned toward baseline (FG, from $80 \pm 8$ to $86 \pm 7$ to $83 \pm 8 \mathrm{mg} / \mathrm{dl}$, at baseline and after 1 and 5 years, respectively, $P<0.011$ year vs baseline, $P=$ NS 5 years vs baseline; FI, $10.9 \pm 8$ to $13.1 \pm 9$ to $10.1 \pm 8 \mu \mathrm{IU} / \mathrm{ml}$ at baseline and after 1 and 5 years, respectively, $P<0.011$ year vs baseline, $P=$ NS 5 years vs baseline), thus reflecting a long-term restoration of insulin sensitivity. However, evaluating rhGH effects according to the genotype, in the 19/19 patients, FG levels remained significantly higher than at baseline, as observed in the short-term metabolic response. Contrary to what has been observed at baseline and after 1 year, $\mathrm{BF} \%$ in the $\mathrm{X} / \mathrm{X}$ group, though slightly higher, was not significantly different from 19/19 and 19/X groups, while MS prevalence was still higher in noncarriers than in other genotype groups $(n=9$, one in $19 / 19$, two in $19 / X$, and nine in $\mathrm{X} / \mathrm{X}, P<0.001$ at $\chi^{2}$-test). Distribution and prevalence of the singular components of the MS did not change after the 5-year rhGH treatment period (data not shown). No difference from basal conditions was observed in any of the other evaluated parameters. No difference in rhGH dose was observed among the three groups. Statistical analysis between the three genotype-groups did not reveal any significant differences in 5 year-rhGH effects on the evaluated parameters.

The present results still hold significance after consideration of possible confounders such as sex, age at diagnosis, and presence of MS and BF\%. GH effects in the different genotype-groups are presented in Table 3.

Table 2 Effects of rhGH during short-term (1 year) treatment in GHD adults $(n=98)$ according to different IGF1 gene promoter genotypes. Significant metabolic changes are shown in bold.

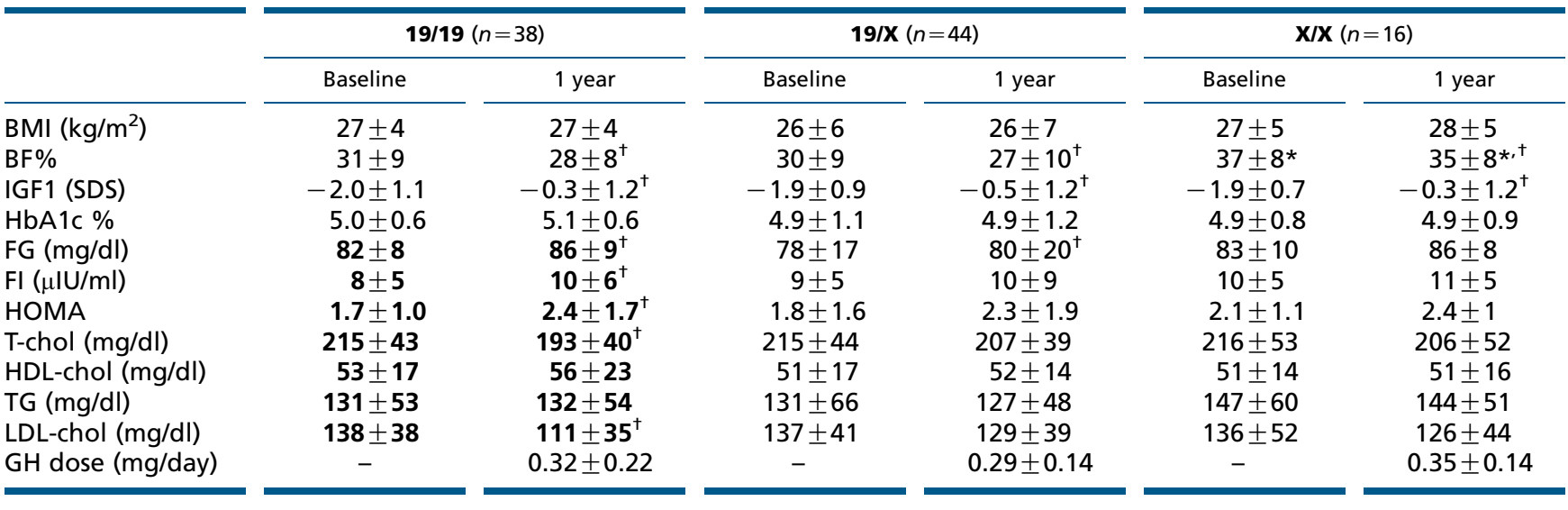

${ }^{\star} P<0.01 \mathrm{X} / \mathrm{X}$ vs $19 / \mathrm{X}$ and $19 / 19 .{ }^{\dagger} P<0.011$ year vs baseline. $\mathrm{BF}$, body fat; $\mathrm{FG}$, fasting glucose; $\mathrm{Fl}$, fasting insulin; T-chol, total cholesterol; TG, triglycerides. 
Table 3 Effects of rhGH during long-term (5 years) treatment in GHD adults $(n=50)$ according to different IGF1 gene promoter genotypes. Significant metabolic changes are shown in bold.

\begin{tabular}{|c|c|c|c|c|c|c|}
\hline & \multicolumn{2}{|c|}{$19 / 19(n=19)$} & \multicolumn{2}{|c|}{$19 / X(n=21)$} & \multicolumn{2}{|c|}{$\mathbf{X} / \mathbf{X}(n=10)$} \\
\hline & Baseline & 5 years & Baseline & 5 years & Baseline & 5 years \\
\hline BMI $\left(\mathrm{kg} / \mathrm{m}^{2}\right)$ & $28 \pm 4$ & $28 \pm 4$ & $27 \pm 4$ & $27 \pm 5$ & $29 \pm 5$ & $30 \pm 6$ \\
\hline $\mathrm{BF} \%$ & $32 \pm 10$ & $27 \pm 9 *$ & $32 \pm 8$ & $26 \pm 8^{*}$ & $35 \pm 3$ & $29 \pm 5 *$ \\
\hline IGF1 (SDS) & $-1.8 \pm 1.0$ & $-0.5 \pm 1.2^{*}$ & $-2.0 \pm 0.8$ & $-0.7 \pm 0.8 *$ & $-1.9 \pm 0.8$ & $-0.6 \pm 0.4 *$ \\
\hline HbA1c \% & $4.9 \pm 0.6$ & $5.1 \pm 0.6$ & $5.2 \pm 0.7$ & $5.1 \pm 0.6$ & $5.0 \pm 0.6$ & $5.4 \pm 0.8$ \\
\hline $\mathrm{FG}(\mathrm{mg} / \mathrm{dl})$ & $79 \pm 7$ & $85 \pm 9 *$ & $79 \pm 9$ & $80 \pm 8$ & $82 \pm 9$ & $86 \pm 8$ \\
\hline $\mathrm{FI}(\mu \mathrm{IU} / \mathrm{ml})$ & $9 \pm 5$ & $10 \pm 6$ & $12 \pm 9$ & $8 \pm 10$ & $12 \pm 5$ & $14 \pm 9$ \\
\hline HOMA & $2.2 \pm 2.2$ & $2.2 \pm 1.2$ & $2.3 \pm 2.0$ & $1.6 \pm 1.9$ & $2.4 \pm 1.1$ & $2.8 \pm 1.5$ \\
\hline T-chol (mg/dl) & $200 \pm 47$ & $182 \pm 37 *$ & $217 \pm 44$ & $195 \pm 35^{*}$ & $206 \pm 52$ & $195 \pm 50$ \\
\hline HDL-chol (mg/dl) & $47 \pm 13$ & $46 \pm 9$ & $47 \pm 15$ & $51 \pm 11$ & $45 \pm 13$ & $46 \pm 10$ \\
\hline TG (mg/dl) & $137 \pm 70$ & $144 \pm 49$ & $128 \pm 69$ & $128 \pm 66$ & $158 \pm 69$ & $146 \pm 59$ \\
\hline LDL-chol (mg/dl) & $127 \pm 39$ & $112 \pm 34^{*}$ & $145 \pm 42$ & $109 \pm 56 *$ & $130 \pm 51$ & $117 \pm 36$ \\
\hline GH dose (mg/day) & - & $0.36 \pm 0.21$ & - & $0.35 \pm 0.13$ & - & $0.37 \pm 0.13$ \\
\hline
\end{tabular}

${ }^{*} P<0.015$ years vs baseline. BF, body fat; FG, fasting glucose; FI, fasting insulin; T-chol, total cholesterol; TG, triglycerides.

\section{Discussion}

In this study, we investigated for the first time the impact of the IGF1 promoter polymorphism on the metabolic response to rhGH in a cohort of adult GHD patients. The allelic distribution was similar in GHD patients and in controls, the $19(\mathrm{CA})$ repeats allele being the most frequent, as previously reported. For this reason, patients were divided according to the presence or absence of the 19(CA) allele.

In our series of GHD adults, both the presence or absence of the WT allele and the length of the microsatellite (number of CA repeats) did not influence the response to rhGH, including increase in IGF1 levels. Independent from rhGH replacement, noncarriers of the WT allele seem to have a less favorable metabolic profile. In fact, in the X/X group, apart from a higher $\mathrm{BF} \%$, a significantly higher prevalence of MS was also observed, both at baseline and during follow-up. This finding does not seem to be influenced either by rhGH replacement or by severity of GHD (no difference in GH peak at stimulation test) or by primary pituitary pathology (no higher prevalence of craniopharyngioma in the noncarrier group). Even though the relatively small number of patients in each group does not allow us to draw consistent conclusions on this topic, the result of a less favorable metabolic profile in noncarriers of the WT allele is in agreement with previous studies in far larger cohorts reporting a higher prevalence of type 2 diabetes and an increased risk of fat accumulation in this genotype $(10,28)$.

Results obtained from longitudinal analysis of rhGH effects within each genotype group suggest that patients carrying the WT allele are more sensitive to rhGH effects both in terms of improvement in lipid profile and worsening of insulin sensitivity, even though no difference in IGF1 levels, either at baseline or during short- and long-term rhGH therapy, was found among the three genotype-groups. Linear multiple regression analyses excluded an eventual influence of possible confounders such as sex, age at diagnosis, and presence of MS and BF\%.

In the last years, many studies evaluated the relationship between IGF1 promoter polymorphism and IGF1 levels, with conflicting results. The first important study on a large population carried out by Vaessen et al. (10) suggested that the presence of alleles 192 (19 CA repeats) or 194 (20 CA repeats) was linked to higher IGF1 levels. On the contrary, studies performed in the following years failed to find a relationships between IGF1 levels and number of CA repeats in the promoter region $(11,12)$ or showed an inverse correlation (13, 14, 15). Similarly, Rosen et al. (16) found that low serum IGF1 levels in men with idiopathic osteoporosis were associated with homozygosity for the 192/192 allele.

The precise role of this polymorphism remains to be clarified. This particular microsatellite is located at a region known to contain specific regulatory elements of the IGF1 gene. Some authors have speculated that allelic variation in this region might lead to changes in the promoter activity altering IGF1 transcription (29) or might be in linkage disequilibrium with another sequence in the promoter region, leading to message stability or circulating IGF1 alterations (30).

Indeed, all these studies have been performed in the attempt to find a correlation between IGF1 biochemical and genetic profile and cardiovascular or neoplastic 
diseases, thus excluding subjects with pathologies regarding GH-IGF1 axis.

Some studies have been performed either in children born small for gestational age (SGA) or affected with GHD, in the attempt to find a relationship among IGF1 gene polymorphism and catch-up growth, response to $\mathrm{GH}$ therapy, or IGF1 levels. Regarding children born SGA, Arends et al. (31) reported an association between the polymorphism of the IGF1 gene and IGF1 levels (lower in subjects carrying the $191 \mathrm{bp}$ allele). However, as underlined in a more recent review by Ester \& Hokken-Koelega (32), among studies investigating an association between the $19(\mathrm{CA})$ repeat allele and prenatal growth, birth size and postnatal growth in SGA, results were conflicting, mostly due to differences in selected populations, data acquisition, and data analysis. As far as children with severe isolated GHD, a recent study has shown that homozygosity for the allele with 19(CA) repeats was associated with a less favorable short- and long-term growth response to rhGH therapy, when compared with other IGF1 genotypes, though no correlation was found between IGF1 serum level and IGF1 genotype (33). By contrast, in the same year, Miletta et al. (34) reported no difference among the various genotypes in rhGH effects in term of final heights.

Till now, only two studies have been performed on this topic in adults with acromegaly (17) and GHD (18), the former reporting an association between IGF1 levels and a particular IGF1 promoter genotype, the latter negating any correlation with serum IGF1 levels or rhGH replacement dose. Regarding the impact of this polymorphism on serum IGF1 levels, our results are in agreement with those reported by Meyer et al. (18) in 133 GHD adults. In this study, authors analyzed by genotype GH-dose after 1 year, IGF1 and IGF1 SDS values, IGF1:GH ratio, and anthropometric data. Concerning the CA repeat promoter polymorphism, no significant difference in GH doses and IGF1 concentration by IGF1 genotype was observed. To the best of our knowledge the work by Meyer et al. is the only report on this topic in GHD adults. Thus, this study was prompted by the lack of data on this issue in GHD adults, along with the conflicting results of previous studies carried out in different populations and, at last but not least, by the still unexplained extreme variability in the response to $\mathrm{rhGH}$ therapy observed in adult patients.

As previously reported by our group for the GHR polymorphism (9), present results indicate that rhGH replacement may influence at least some metabolic parameters typical of GHD adult syndrome in a slightly different manner, according to the different IGF1 promoter genotype, with the improvement in lipid profile and the worsening of insulin sensitivity being more pronounced in patients carrying the 19(CA) allele. However, the main question arising from the present data is how this polymorphism may play a role in the metabolic response to rhGH, without exerting any impact in IGF1 serum levels.

Definitely, circulating IGF1 concentrations do not reflect the actual concentrations at local tissues, and it is tempting to speculate that local IGF1 production and its paracrine effect, not mirrored by the hepatic endocrine secretion, might mediate GH action in specific tissues such as bone, muscle, or adipose tissues. On this connection, it is possible that the IGF1 promoter polymorphism, altering IGF1 transcription or half-life, may alter IGF1 production at a local level, thus contributing to mediate GH metabolic effects in a different manner, according to a different genotype. This hypothesis might explain the impact of this polymorphism in the metabolic response to $\mathrm{rhGH}$, observed in our cohort of GHD adults, in terms of improvement of lipid profile and worsening of insulin resistance, enhanced in patients carrying the WT allele.

In conclusion, the present data suggest that the IGF1 promoter genotype, which does not seem to play any role in the determination of the inter-individual variability of rhGH effects in terms of circulating IGF1 levels, may influence the metabolic response to replacement therapy. Ongoing studies will widen the long-term group of patients and give more strength to present results. Further studies, also at a molecular level, are needed to better clarify the functional role of this polymorphism and the complex relationships between different IGF1 levels and metabolic response at tissue level.

\section{Declaration of interest}

$\mathrm{P}$ Beck-Peccoz received a research grant form Pfizer. The other authors have nothing to disclose.

\section{Funding}

This work was partially supported by Fondazione IRCCS Ca' Granda, Ospedale Maggiore Policlinico.

\section{References}

1 De Boer H, Block GJ \& van der Veen VA. Clinical aspects of growth hormone deficiency in adults. Endocrine Reviews 199516 63-86. (doi:10.1210/er.16.1.63)

2 Salomon F, Cuneo RC, Hesp R \& Sonksen PH. The effects of treatment with recombinant human growth hormone on body composition and 
metabolism in adult with growth hormone deficiency. New England Journal of Medicine 1989321 1797-1803. (doi:10.1056/ NEJM198912283212605)

3 Drake WM, Coyte D, Camacho-Hubner C, Jivanji NM, Kaltsas O, Wood DF, Trainer PJ, Grossman AB, Besser GM \& Monson JP. Optimizing growth hormone replacement therapy by dose titration in hypopituitary adults. Journal of Clinical Endocrinology and Metabolism 199883 3913-3919. (doi:10.1210/jc.83.11.3913)

4 Motlich ME, Clemmons DR, Molozowski S, Merriam GR \& Vance ML. Evaluation and treatment of adult growth hormone deficiency: an Endocrine Society Clinical Practice guideline. Journal of Clinical Endocrinology and Metabolism 201196 587-1609. (doi:10.1210/ jc.2011-0179)

5 Johannsson G, Bjarnason R, Bramnert M, Carlsson LM, Degerbled M, Manhem P, Rosen T, Thorén M \& Bengtsson BA. The individual responsiveness to growth hormone (GH) treatment in GH-deficient adults is dependent on the level of GH-binding protein body mass index, age and gender. Journal of Clinical Endocrinology and Metabolism 199681 1575-1581. (doi:10.1210/jc.81.4.1575)

6 Pantel J, Machinis K, Sobrier ML, Duquesnoy P, Goossens M \& Amselem S. Species-specific alternative splicing mimicry at the growth hormone receptor locus revealed by the lineage of retroelements during primate evolution. Journal of Biological Chemistry 2000275 18664-18669. (doi:10.1074/jbc.M001615200)

7 Dos Santos SC, Essioux L, Teinturier C, Tauber M, Goffin V \& Bougneres P. A common polymorphism of the growth hormone receptor is associated with increased responsiveness to growth hormone. Nature Genetics 200436 720-724. (doi:10.1038/ng1379)

8 Wassenaar MJ, Dekkers OM, Pereira AM, Wit JM, Smit JW, Biermasz NR \& Romijn JA. Impact of the exon 3-deleted growth hormone (GH) receptor polymorphism on baseline height and on the growth response to recombinant human GH therapy in GH-deficient (GHD) and nonGHD children with short stature: a systematic review and metaanalysis. Journal of Clinical Endocrinology and Metabolism 200994 3721-3730. (doi:10.1210/jc.2009-0425)

9 Giavoli C, Ferrante E, Profka E, Olgiati L, Bergamaschi S, Ronchi CL, Verrua E, Filopanti M, Passeri E, Montefusco L et al. Influence of the d3GH receptor polymorphism on the metabolic and biochemical phenotype of GH-deficient adults at baseline and during short- and long-term recombinant human GH replacement therapy. European Journal of Endocrinology 2010163 361-368. (doi:10.1530/EJE-10-0317)

10 Vaessen N, Heutink P, Janssen JA, Witteman JC, Testers L, Hofman A, Lamberts SW, Oostra BA, Pols HA \& van Duijn A. A polymorphism in the gene for IGF-I functional properties and risk for type 2 diabetes and myocardial infarction. Diabetes 200150 637-642. (doi:10.2337/ diabetes.50.3.637)

11 Freylig TM, Hattersley AT, McCarthy A, Holly J, Mitchell SM, Gloyn AL, Owen K, Davies D, Davey Smith G \& Ben-Shlomo Y. A putative functional polymorphism in the IGF-I gene. Association studies with type 2 diabetes, adult height, glucose tolerance, and fetal growth in U.K. populations. Diabetes 200251 2313-2316. (doi:10.2337/diabetes. 51.7.2313)

12 Allen NE, Davey GK, Key TJ, Zhang S \& Narod SA. Serum insulin-like growth factor I (IGF-I) concentration in men is not associated with the cytosine-adenosine repeat polymorphism in the IGF-I gene. Cancer Epidemiology, Biomarkers \& Prevention 200211 319-320.

13 Rietveld I, Janssen JA, van Rossum EF, Houwing-Duistermaat JJ, Rivadeneira F, Hofman A, Pols HA, van Duijn CM \& Lamberts SW. A polymorphic CA repeat in the IGF-I gene is associated with genderspecific differences in body height, but has no effect on the secular trend in body height. Clinical Endocrinology 200461 195-203. (doi:10.1111/j.1365-2265.2004.02078.x)

14 Missmer SA, Haiman CA, Hunter DJ, Willett WC, Colditz GA, Speizer FE, Pollak MN \& Hankinson SE. A sequence repeat in the insulin-like growth factor-1 gene and risk of breast cancer. International Journal of Cancer 2002100 332-336. (doi:10.1002/ijc.10473)
15 Yu H, Li BD, Smith M, Shi R, Berkel HJ \& Kato I. Polymorphic CA repeats in the IGF-I gene and breast cancer. Breast Cancer Research and Treatment 200270 117-122. (doi:10.1023/A:1012947027213)

16 Rosen CJ, Kurland ES, Vereault D, Adler RA, Rackoff PJ, Craeig WY, Witte S, Rogers J \& Bilezikian JP. Association between serum insulin growth factor-I (IGF-I) and a simple sequence repeat in the IGF-I gene: implication for genetic studies of bone mineral density. Journal of Clinical Endocrinology and Metabolism 199883 2286-2290. (doi:10.1210/ jc.83.7.2286)

17 Akin F, Turgut S, Cirak B \& Kursunluoglu R. IGF(CA)19 and IGFBP-3-202A/C gene polymorphism in patients with acromegaly. Growth Hormone \& IGF Research 201020 399-403. (doi:10.1016/j.ghir. 2010.09.001)

18 Meyer S, Schaefer S, Ivan D, Stolk L, Arp P, Uitterlinden GA, Nawroth PP, Plöckinger U, Stalla GK, Tuschy U et al. Growth hormone dose in growth hormone-deficient adults is not associated with IGF-I gene polymorphisms. Pharmacogenomics 200910 293-302. (doi:10.2217/14622416.10.2.293)

19 Ghigo E, Aimaretti G, Giannotti L, Bellone J, Arvat E \& Camanni F. New approach to the diagnosis of growth hormone deficiency in adults. European Journal of Endocrinology 1996134 352-356. (doi:10.1530/eje.0. 1340352)

20 Corneli G, Di Somma C, Baldelli R, Rovere S, Gasco V, Croce CG, Grottoli S, Maccario M, Colao A, Lombardi G et al. The cut-off limits of the GH response to GH-releasing hormone-arginine test related to body mass index. European Journal of Endocrinology 2005153 257-264. (doi:10.1530/eje.1.01967)

21 Porretti S, Giavoli C, Ronchi C, Lombardi G, Zaccaria M, Valle D, Arosio M \& Beck-Peccoz P. Recombinant human GH therapy and thyroid function in a large group of adult GH-deficient patient: when does L-T(4) therapy become mandatory? Journal of Clinical Endocrinology and Metabolism 200287 2042-2045. (doi:10.1210/jc.87.5.2042)

22 Giavoli C, Libè R, Corbetta S, Ferrante E, Lania A, Arosio M, Spada A \& Beck-Peccoz P. Effect of recombinant human growth hormone (GH) replacement on the hypothalamic-pituitary-adrenal axis in adult GH-deficient patients. Journal of Clinical Endocrinology and Metabolism 200489 5397-5401. (doi:10.1210/jc.2004-1114)

23 Matthews DR, Hosker JP, Rudensky AS, Naylor BA, Tracher DF \& Turner RC. Homeostasis model assessment: insulin resistance and $\beta$-cell function from fasting plasma glucose and insulin concentrations in man. Diabetologia 198528 412-419. (doi:10.1007/BF00280883)

24 Friedwald WT, Levy RI \& Friedrickson DS. Estimation of the concentration of low-density lipoprotein cholesterol in plasma, without use of the preparative ultracentrifuge. Clinical Chemistry 1972 18 499-502.

25 Segal KR, Van Loan M, Fitzgerald PI, Hodgdon JA \& Van Itallie TB. Lean body mass estimation by bioelectrical impedance analysis: a four-site cross validation study. American Journal of Clinical Nutrition 198847 7-14.

26 Pichard C, Kyle UG, Bracco D, Slosman DO, Morabia A \& Schutz Y. Reference values of fat-free and fat masses by bioelectrical impedance analysis in 3393 healthy subjects. Nutrition 200016 245-254. (doi:10.1016/S0899-9007(00)00256-2)

27 National Cholesterol Education Program (NCEP) Expert Panel on Detection, Evaluation, and Treatment of High Blood Cholesterol in Adults (Adult Treatment Panel III). Third Report of the National Cholesterol Education Program (NCEP) Expert Panel on Detection, Evaluation, and Treatment of High Blood Cholesterol in Adults (Adult Treatment Panel III) final report. Circulation 2002106 3143-3421.

28 Voorhoeve PG, van Rossum EF, Te Velde SJ, Koper JW, Kemper HC, Lamberts SW \& de Waal HA. Association between an IGF-I gene polymorphism and body fatness: differences between generations. European Journal of Endocrinology 2006154 379-388. (doi:10.1530/ eje.1.02101)

29 West CA, Arnett TR \& Farrow SM. Expression of IGF-I mRNA variants in rat bone. Bone 199619 41-46. (doi:10.1016/8756-3282(96)00105-6) 
30 Naylor LH \& Clark EM. d(TG $)_{n}: d(C A)_{n}$ sequences upstream of the rat prolactin gene from Z-DNA and inhibit gene transcription. Nucleic Acids Research 199018 1595-1600. (doi:10.1093/nar/18.6.1595)

31 Arends N, Johnston L, Hoekken-Koelega A, Van Duijn C, De Ridder M, Savage M \& Clark A. Polymorphism in the IGF-I gene: clinical relevance for short children born small for gestational age (SGA). Journal of Clinical Endocrinology and Metabolism 200287 2720-2724. (doi:10.1210/ jc.87.6.2720)

32 Ester WA \& Hoekken Koelega AC. Polymorphism in the IGFI and IGFI R genes and children born small for gestational age: results of large population studies. Best Practice \& Research. Clinical Endocrinology \& Metabolism 200822 415-431. (doi:10.1016/j.beem.2008.03.001)
33 Costalonga EF, Antonini SR, Guerra G Jr, Coletta RR, Franca MM, Braz AF, Mendonca BB, Arnhold IJ \& Jorge AA. Growth hormone pharmacogenetics: the interactive effect of a microsatellite in the IGF-I promoter region with the GHR-exon 3 and -202 A/C IGFBP3 variants on treatments outcomes of children with severe GH deficiency.

Pharmacogenomics Journal 201212 439-445. (doi:10.1038/tpj.2011.13)

34 Miletta MC, Scheidegger UA, Giordano M, Bozzola M, Pagani S, Bona G, Dattani M, Hindmarsh PC, Petkovic V, Oser-Meier M et al. Association of the (CA)n repeat polymorphism of insulin-like growth factor-I and -202 A/C IGF-binding protein-3 promoter polymorphism with adult height in patients with severe growth hormone deficiency. Clinical Endocrinology 201276 683-690. (doi:10.1111/j.1365-2265.2011.04267.x)

Received 22 July 2013

Revised version received 31 October 2013

Accepted 11 November 2013 